\title{
Descrição de ovos e estádios ninfais de Triatoma carcavalloi (Hemiptera, Reduviidae) por meio de microscopia óptica
}

\author{
José Jurberg, Cleber Galvão, Carolina M. dos Santos \& Morgana B. A. Rangel
}

Laboratório Nacional e Internacional de Referência em Taxonomia de Triatomíneos, Instituto Oswaldo Cruz - Fiocruz. Av. Brasil 4365, 21045-900 Rio de Janeiro, RJ. (jjurberg@ioc.fiocruz.br)

\begin{abstract}
Description of eggs and nymphs of Triatoma carcavalloi through optical microscopy. Triatoma carcavalloi Jurberg, Rocha \& Lent, 1998 in its original description was related to T. rubrovaria (Blanchard, 1843) and T. circummaculata (Stäl, 1859). Here eggs and nymphs of T. carcavalloi are described using optical microscopy to provide new parameters to be used in Triatominae's taxonomy. Eggs showed the operculum and surface with pentagonal and hexagonal cells, with small fractures and punctuations randomly distributed and are similar to T. rubrovaria, T. circummaculata and T. infestans Klug, 1834. Nymphs are different from all species related to T. carcavalloi primordially in color and size. Morphological differences were found in the five nymphal stages, but following the same pattern of color in head, thorax, legs and abdomen.
\end{abstract}

KEYWORDS. Chagas disease, vectors, Triatominae, taxonomy, external morphology.

RESUMO. Triatoma carcavalloi Jurberg, Rocha \& Lent 1998, foi descrita como espécie afim de T. rubrovaria (Blanchard, 1843 ) e $T$. circummaculata (Stäl, 1859). São descritos os ovos e ninfas de T. carcavalloi por meio de microscopia óptica para fornecer novos parâmetros a serem utilizados na taxonomia dos Triatomímeos. Os ovos apresentam semelhanças com T. rubrovaria, T. circummaculata e T. infestans Klug, 1834, com ornamentações tanto na superfície como no opérculo, com células pentagonais e hexagonais, com pequenas fraturas e pontuações distribuídas de forma aleatória. As ninfas se diferenciam de todas as espécies a ela relacionadas, principalmente pela coloração e tamanho. Cada um dos cinco estádios ninfais apresenta diferenças morfológicas, no entanto, o padrão de coloração da cabeça, tórax, pernas e abdômen se mantêm, em todos os estádios.

PALAVRAS-CHAVE. Doença de Chagas, vetores, Triatominae, taxonomia, morfologia externa.

Triatoma carcavalloi Jurberg, Rocha \& Lent 1998, foi descrita como espécie afim de $T$. rubrovaria (Blanchard, 1843) e T. circummaculata (Stäl, 1859), tendo como base seus aspectos cromáticos e distribuição geográfica. No entanto, inúmeros aspectos morfológicos como ângulo anterior do pronoto aguçado, comprimento e largura da cabeça, proporções do rostro, tamanho dos olhos, abdômen menor; e das características da genitália feminina com gonocoxito do nono segmento diferente e de aspecto arredondado evidenciaram a existência de um novo táxon (JuRBERG et al.,1998b). Sua distribuição permanece restrita ao Estado do Rio Grande do Sul (GALVÃo et al., 2003).

Posteriormente, CARCAVALlo et al. (2000) incluíram essa espécie no "complexo infestans" juntamente com $T$. infestans (Klug, 1834); T. platensis Neiva, 1913; T. delpontei Romana \& Abalos, 1947; T. rubrovaria e T. melanosoma Martinez, Olmedo \& Carcavallo, 1987, por compartilharem semelhanças morfológicas e/ou ecológicas.

No entanto, trabalhos mais recentes envolvendo técnicas moleculares indicam que $T$. rubrovaria e $T$. circummaculata estão muito mais próximas entre si que das espécies que fazem parte do "complexo infestans" (HYPSA et al., 2002; SAINZ et al., 2004).

Os primeiros espécimes foram coletados em domicílios, atraídos pela luz, nos municípios de Santana do Livramento, Canguçu, Jaguarão e Dom Feliciano, distantes entre si, no Estado do Rio Grande do Sul (JuRBERG et al., 1998b). No entanto, ela é considerada uma espécie silvestre e autóctone, com hábitos rupestres, prevalecendo em ambientes pedregosos naturais, cercas e outros ecótopos artificiais (RuAs-Neto \& Corseuil, 2002).

Sua relevância como vetor de Trypanosoma cruzi Chagas, 1909 é ainda desconhecida, bem como seu comportamento biológico. No entanto, deve-se considerar o fato de que todos os triatomíneos são vetores potenciais e de que os nichos vazios, antes ocupados por vetores primários, passam a ser ocupados por espécies consideradas secundárias. No Brasil, por exemplo, T. sordida (Stäl, 1859), T. pseudomaculata Corrêa \& Espínola, 1964 e Panstrongylus megistus (Burmeister, 1835) são espécies que costumam invadir domicílios antes ocupados pelo T. infestans.

Triatoma carcavalloi é considerada uma espécie litófila e tem sido encontrada convivendo com $T$. rubrovaria e T. circummaculata em interstícios de rochas sugando hemolinfa de blatídeos. O ciclo biológico de ninfas de $1^{\circ}$ ao $5^{\circ}$ estádio, em laboratório, foi concretizado às custas de hemolinfa de Dyctioptera (Lorosa et al., 2000; RUAS- NETO et al., 2001).

O presente trabalho tem o intuito de descrever a morfologia dos ovos e estádios ninfais de T. carcavalloi, enfatizando ainda a ornamentação do exocório dos ovos por meio de microscopia óptica. Esses estudos são importantes na busca de novos parâmetros a serem utilizados na taxonomia dos triatomíneos, não só para ampliar o conceito específico, mas também para fornecer subsídios na elaboração de uma chave dicotômica que irá auxiliar na identificação precisa das espécies de triatomíneos. 
A morfologia de ovos e ninfas dos triatomíneos tem sido alvo de estudos de diversos autores (CARCAVAllo et al., 1975, 1978; JimÉnEZ \& FuENTES, 1981; GONÇAlves et al., 1985; JuRBERG et al., 1986, 1991a, b, 1998a, 2002; MASCARENHAS, 1987; Costa et al., 1991; Jurberg \& Vogel, 1994; JuRberg \& CAMPOS, 1995; Rocha et al., 1996; GALíndEZ-Giron et al., 1999; SiLva et al., 2000).

Segundo Rocha et al. (1996), a caracterização das ninfas é um fator importante para o conhecimento da epidemiologia da doença de Chagas, podendo indicar o seu poder vetorial, uma vez que nas áreas onde são feitas as medidas de controle, o encontro de ovos, ninfas e exúvias pode indicar reinfestação, desde que as espécies sejam corretamente identificadas.

Os resultados das intervenções em áreas de vigilância demonstram que as formas adultas estão sendo cada vez menos encontradas e, em contrapartida, as formas imaturas são cada vez mais freqüentes (BARATA, 1981). Dessa maneira, se torna importante o conhecimento das formas imaturas em função do reconhecimento mais preciso visando o controle do vetor.

\section{MATERIAL E MÉTODOS}

Os ovos e as ninfas utilizadas são provenientes de colônias aclimatadas e mantidas desde 1998 no Insetário do Laboratório Nacional e Internacional de Referência em Taxonomia de Triatomíneos, Instituto Oswaldo Cruz, alimentadas mensalmente com sangue de ave (Columbia livia Gmelin, 1789) e semanalmente, de acordo com a necessidade da colônia, é oferecido sangue de roedor (Mus musculus Linnaeus, 1758).

Ovos. Foram utilizados cinco ovos. O opérculo foi retirado e montado entre lâmina e lamínula com fenol. Posteriormente, fragmentou-se esses ovos e montou-se entre lâmina e lamínula, com álcool, para que fossem feitas as ilustrações com auxílio de uma câmara clara acoplada a um microscópio estereoscópico.

Ninfas. Foi observada uma ninfa de cada estádio. Selecionou-se as ninfas recém eclodidas por apresentarem menos conteúdo intestinal. As mesmas foram sacrificadas após, aproximadamente, dois a três dias para que sua quitina estivesse bem enrijecida e em baixa temperatura para conservar as características estruturais e cromáticas. Em seguida, as ninfas foram aquecidas separadamente em solução de hidróxido de potássio a $10 \%$ até que toda sua matéria orgânica fosse destruída e as estruturas esclerotizadas se tornassem mais flexíveis e transparentes. Feito isso, foram transferidas para o fenol para desidratação e, logo após, para o creosoto. Para finalizar, os espécimes foram montados entre lâmina e lamínula com Bálsamo do Canadá e desenhados em câmara clara acoplada a um microscópio estereoscópico.

\section{RESULTADOS}

Ovos. Coloração esbranquiçada imediatamente após a postura, atingindo coloração avermelhada após a embrionia. Relação do diâmetro do opérculo e a largura máxima do ovo 1:2,01; comprimento total médio de 1,51 \pm
0,02 mm. Proporção entre o comprimento total e o diâmetro do opérculo 1:2,96.

O corpo do ovo e o opérculo apresentam o exocório de superfície lisa ornamentado com células hexagonais e pentagonais, justapostas, sendo as do opérculo, em sua maioria, hexagonais, com algumas pentagonais, contendo pequenas fraturas e, no corpo, presença de pontuações distribuídas aleatoriamente em sua extensão (Fig. 1). Na borda do opérculo foram vizualizadas projeções dilatadas no ápice que permitem a fixação deste no ovo (Fig. 2). Não possuem "colo" ou "colarinho" e a borda corial é contígua ao plano do opérculo e da casca.

Ninfas. Todos os estádios seguem o mesmo padrão de coloração na cabeça, tórax, pernas e abdômen, passando de castanho claro na ninfa de $1^{\circ}$ estádio até o castanho escuro na ninfa de $5^{\circ}$ estádio. Apresentam áreas claras na região ventral da cabeça, antenas e pernas.

$1^{\circ}$ estádio (Fig. 3). Comprimento total médio 2,85 $\mathrm{mm}$. Coloração castanha clara, com tegumento recoberto de uma pilosidade esparsa constituída por microscópicas cerdas decumbentes implantadas em tubérculos setíferos, da mesma cor do tegumento que lhe conferem um aspecto rugoso, menos perceptíveis e mais espaçados, de acordo com a evolução dos estádios.

Antenas inseridas em tubérculos laterais localizados no limite do terço anterior da cabeça. Coloração castanha similar em todos os segmentos antenais com cerdas regularmente distribuídas e espaçadas. O terceiro e o quarto segmentos recobertos de sensilas curtas entremeadas de cerdas mais longas. Proporções entre os artículos da antena 1:1,8:2,5:2,7.

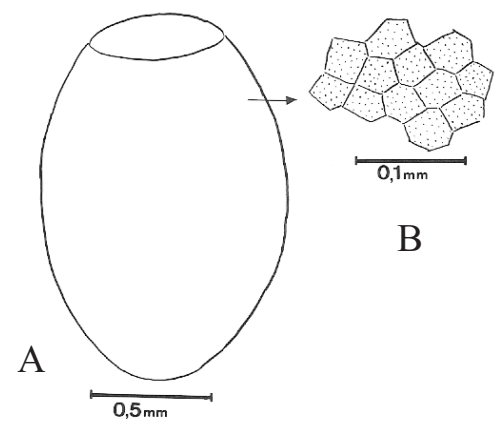

Fig. 1. Triatoma carcavalloi Jurberg, Rocha \& Lent, 1998; Ovo: A, corpo com superfície lisa; B, ornamentação, vista através de microscopia óptica e evidenciando as células pentagonais e hexagonais justapostas.

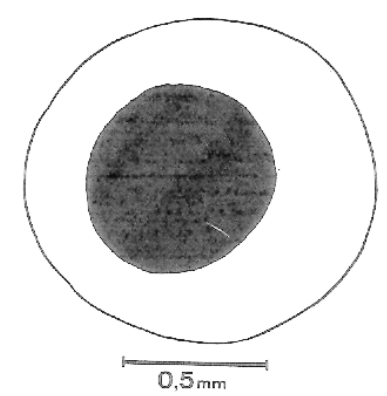

Fig. 2. Triatoma carcavalloi Jurberg, Rocha \& Lent 1998; Ovo: Visão geral, por cima, sem o opérculo. 
Olhos compostos de coloração negra constituída por omatídeos circulares afastados uns dos outros. Jugas de ápice arredondado atingindo a extremidade do tubérculo antenífero. Na extremidade da gena há uma protuberância com $1+1$ cerdas implantadas em seu ápice. Existe ainda 1+1 cerdas no ápice do clípeo de coloração mais clara. Sulco pós-ocular bem demarcado. Rostro retilíneo com o $3^{\circ}$ segmento atingindo a borda anterior do proesterno quando em repouso e de coloração menos intensa que a cabeça. Proporções entre os artículos do rostro: $1: 2,4: 1,4$.

Tórax de coloração castanha, dorsalmente ornamentada com poucas cerdas implantadas em tubérculos distribuídos de forma aleatória pelo tegumento granuloso contendo cerdas na região mediana. Pronoto de forma trapezoidal, exibindo o colar com ângulos anterolaterais e 1+1 tubérculos localizados nas bordas laterais com microscópicas cerdas decumbentes e com o úmero de aspecto arredondado. Tubérculos discais pouco visíveis divididos em duas partes iguais por uma linha mediana longitudinal de coloração mais clara. Mesonoto formado por $1+1$ placas retangulares, com $1+1$ reentrâncias na borda inferior, com tegumento granuloso. Metanoto de coloração mais intensa, formado por $1+1$ placas retangulares bastante separadas de bordas internas sinuosas, superior e inferior divergentes, externas limitadas por tubérculos setíferos justapostos.

Pernas apresentando coxas, trocanteres, articulações entre fêmures e tíbias com a porção mediana basal mais escura, tarsos cobertos por cerdas longas e levemente entrecortadas de coloração similar ao resto do corpo.

Abdômen oval, membranoso e enrugado de coloração castanha clara, estreito e formado por nove segmentos nitidamente demarcados, separados entre si por uma membrana do $1^{\circ}$ ao $8^{\circ}$ segmentos e ornamentados por tubérculos setíferos dispostos em duas fileiras paralelas do $2^{\circ}$ ao $7^{\circ}$ segmento, sem manchas conexivais.

$2^{\circ}$ estádio (Fig. 4). Comprimento médio total de 5,13 $\mathrm{mm}$. Coloração castanha clara apresentando cerdas implantadas em tubérculos dispostos em fileiras na região da fronte e de forma aleatória no vértex.

Olhos com omatídeos mais próximos. Entre a largura da região anteocular e pós-ocular a proporção média é de 1:2,5. Proporção média entre os artículos antenais de 1:2,4:2,9:3,1; e a proporção média entre os segmentos do rostro é de 1:2,3:1,3. Antenas de borda ondulada, apresentando coloração castanha mais intensa observada no $1^{\circ}, 2^{\circ}$ e $3^{\circ}$ segmentos antenais. $\mathrm{O} 4^{\circ}$ segmento antenal possui coloração similar aos outros segmentos sendo a porção superior amarelada.

Tórax de coloração mais escura coberto por cerdas inseridas em tubérculos dispostos aleatoriamente, com ângulos antero-laterais claros e protuberantes, úmero apresentando extremidades glabras, tubérculo discal visível.

Mesonoto constituído por 1+1 placas quitinizadas, justapostas separadas por uma estreita área membranosa. Abdômem oval membranoso com aspecto enrugado recoberto de cerdas implantadas em tubérculos. Manchas

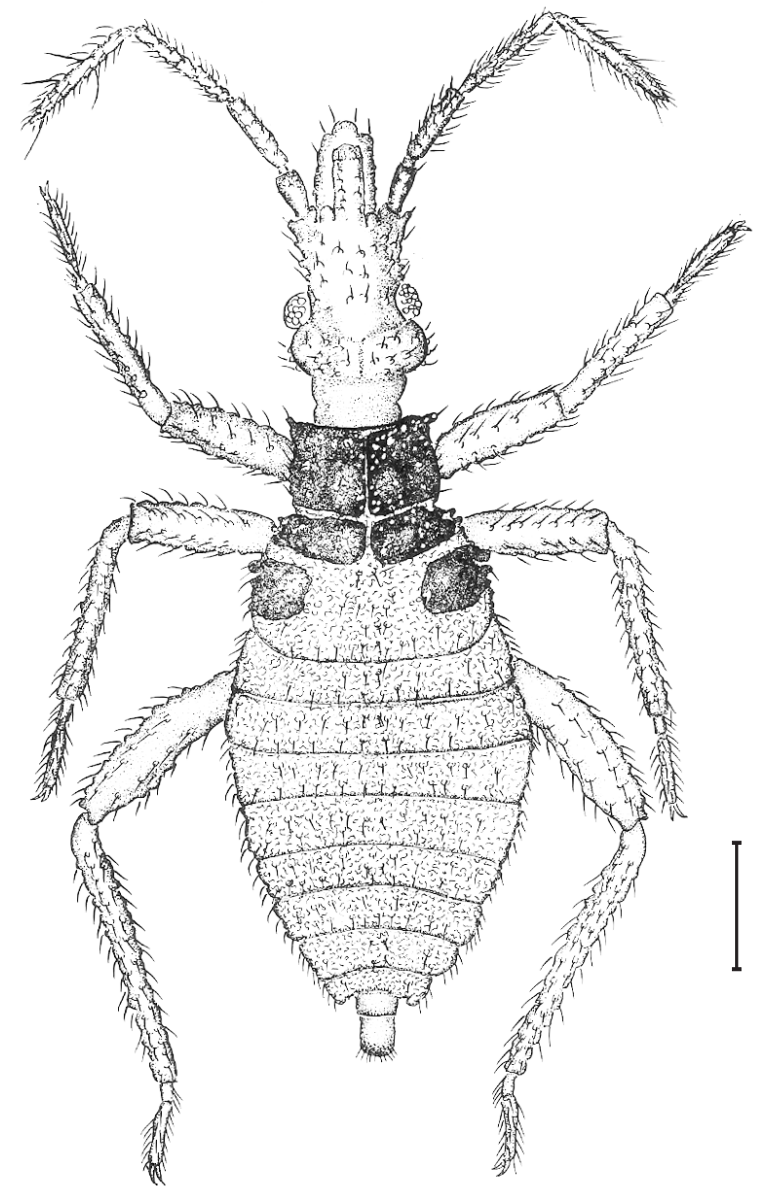

Fig. 3. Triatoma carcavalloi Jurberg, Rocha \& Lent, 1998; Ninfa de $1^{\circ}$ estádio. Barra, 0,5 mm.

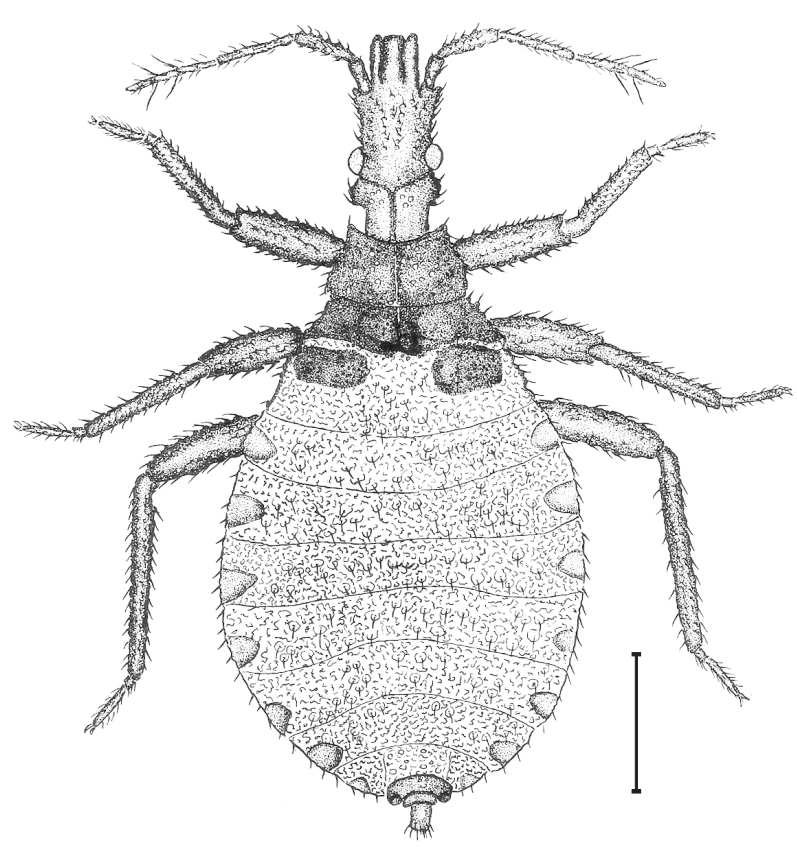

Fig. 4. Triatoma carcavalloi Jurberg, Rocha \& Lent, 1998; Ninfa de $2^{\circ}$ estádio. Barra, $1 \mathrm{~mm}$. 
conexivais presentes. Área central glabra pouco distinta na borda posterior.

$3^{\circ}$ estádio (Fig. 5). Comprimento médio total de 5,47 $\mathrm{mm}$. Coloração geral castanha escura.

Cerdas implantadas em tubérculos setíferos desde a região anteocular até o inicio do pescoço, em duas fileiras centrais paralelas e jugas dediformes. Entre a largura da região anteocular e da região pós-ocular a proporção média é de 1:3,3.

Antenas de coloração castanha escura nos três primeiros segmentos; base do $4^{\circ}$ mais clara. Proporção média entre os artículos antenais 1:2,4:2,5:2,8. Rostro com proporções médias 1:2,1:1,2.

Tórax com tubérculo discal bem visível com pequenas cerdas inseridas. Abdômen com cerdas curtas e 2+2 áreas glabras na borda lateral, $1+1$ subapical e uma central do $2^{\circ}$ ao $6^{\circ}$ tergito. Bordas laterais limitadas por tubérculos setíferos, justapostos, que lhe dão um aspecto ondulado característico, apresentando manchas conexivais.

$4^{\circ}$ estádio (Fig. 6). Comprimento médio total de 7,67 $\mathrm{mm}$. Coloração castanha escura.

Proporção média entre a largura da região anteocular e da região pós-ocular 1:3,6. Artículos antenais com proporções médias 1:3,1:2,9:2,6. Proporções médias entre os segmentos do rostro 1:2:1.

Tórax com úmeros e ângulos antero-laterais de coloração alaranjada apresentando forma triangular bem característica. Na região do pronoto $1+1$ áreas glabras centrais. Mesonoto com 1+1 manchas alaranjadas nas extremidades. Tecas alares evidenciadas; esboço de 1+1 tecas alares cujo $1^{\circ}$ par atinge a borda anterior do metatorax e o $2^{\circ}$ atinge o $1^{\circ}$ urotergito.

Pernas de coloração castanha, com cerdas curtas, levemente entrecortadas, implantadas em tubérculos setíferos.

Abdômen com o conexivo apresentando manchas alaranjadas.

$5^{\circ}$ estádio (Fig. 7). Comprimento médio total de 10,69 $\mathrm{mm}$. Coloração castanha escura.

Cabeça com cerdas implantadas em tubérculos localizados aleatoriamente nas bordas laterais da região anteocular e interocular compondo o que caracteriza um tegumento granuloso. Jugas com formato dediforme.

Olhos compostos negros, constituídos por vários omatídeos justapostos. Proporção média entre a região anteocular e a largura da região pós-ocular 1:3,5. Artículos antenais com proporções médias de 1:3,4:2,8:2,1. Os três primeiros segmentos antenais e a base do $4^{\circ}$ apresentam coloração castanha escura. Proporções médias entre os segmentos do rostro 1:2,1:1,1.

Tórax castanho escuro, com ângulos antero-laterais e umerais mais claros, $1+1$ áreas de aspecto reniforme no mesotórax. Tubérculos discais, úmeros avermelhados; apresenta esboço das asas cujo ápice ultrapassa o $2^{\circ}$ segmento abdominal; manchas conexivais com a parte basal mais escurecida.

Abdômen com manchas avermelhadas. Todos os segmentos apresentam áreas glabras salientes, circundadas pelo tegumento granuloso. Tecas alares atingem a borda inferior do $3^{\circ}$ segmento abdominal.

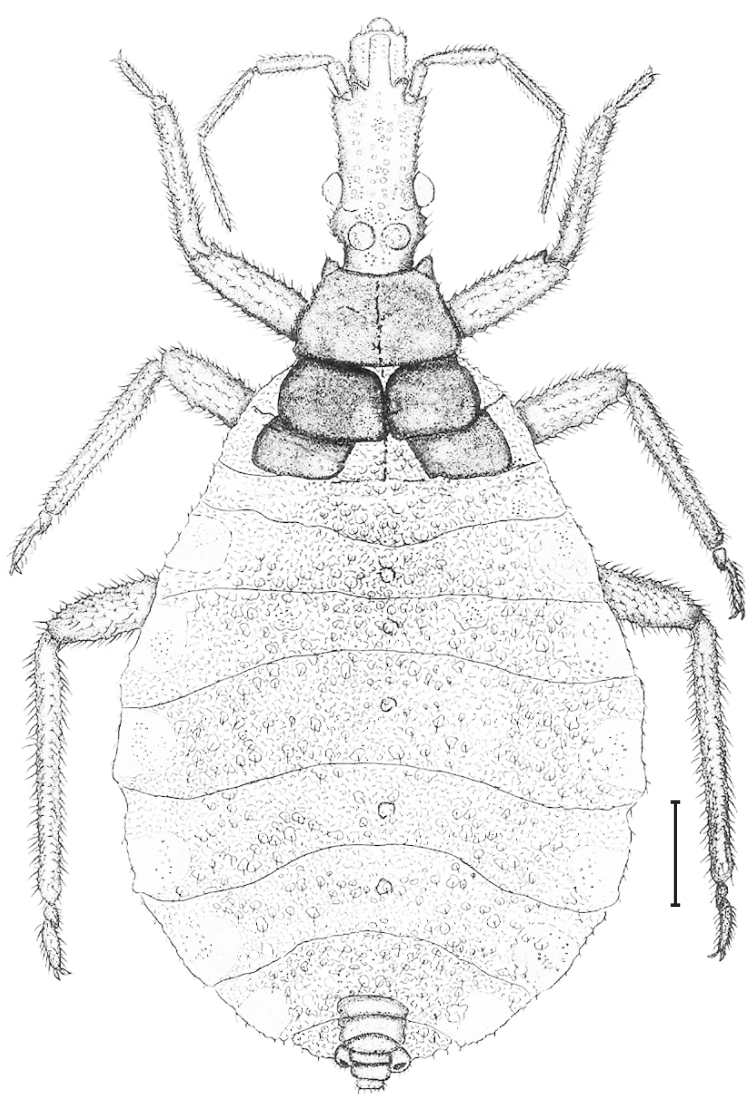

Fig. 5. Tratoma carcavalloi Jurberg, Rocha \& Lent, 1998; Ninfa de $3^{\circ}$ estádio. Barra, $1 \mathrm{~mm}$.

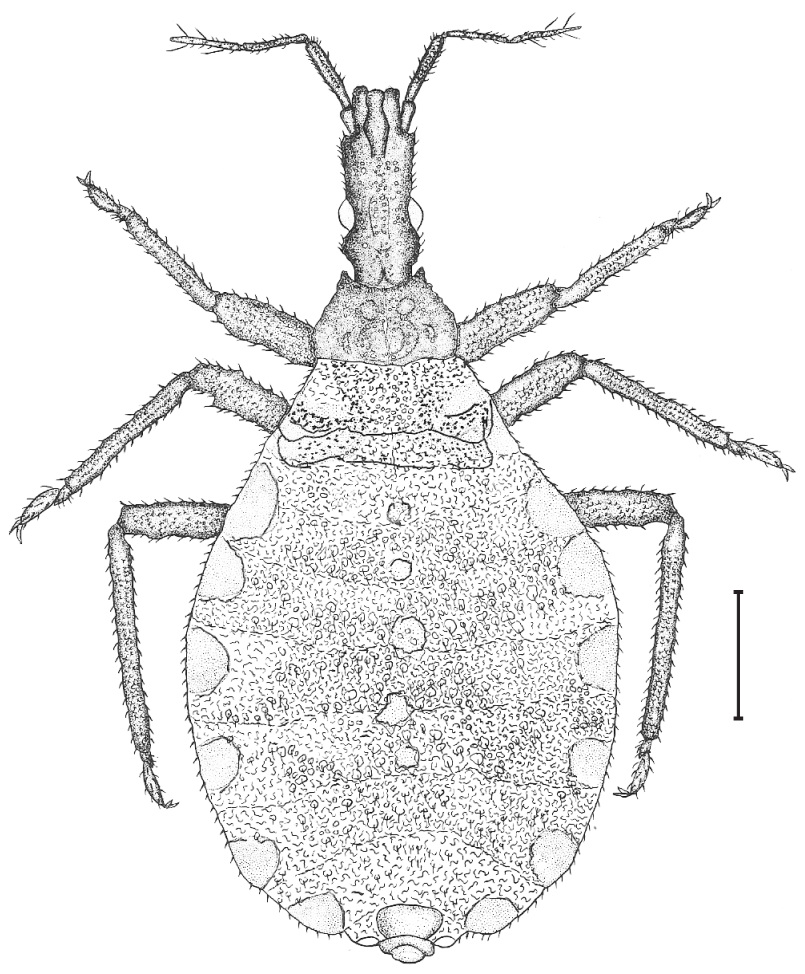

Fig. 6. Triatoma carcavalloi Jurberg, Rocha \& Lent, 1998; Ninfa de $4^{\circ}$ estádio. Barra, $2 \mathrm{~mm}$. 


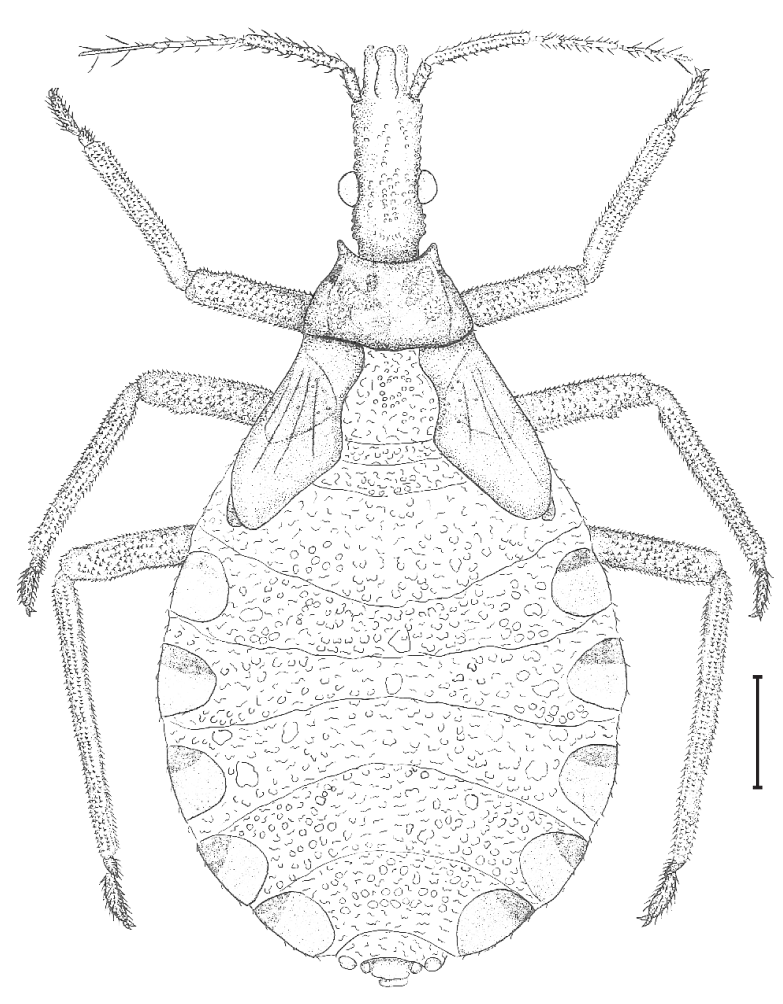

Fig. 7. Triatoma carcavalloi Jurberg, Rocha \& Lent, 1998; Ninfa de $5^{\circ}$ estádio. Barra, $2 \mathrm{~mm}$.

\section{DISCUSSÃO}

A importância do estudo dos ovos dos triatomíneos teve início com PinTo (1924), que descreveu ovos de Triatoma brasiliensis Neiva, 1911 diferenciandoos de outras espécies do gênero Triatoma encontradas no Brasil.

Posteriormente, Galliard (1935) estabeleceu caracteres macroscópicos que deveriam ser utilizados para estudar os ovos como tamanho, forma, coloração, tipo de exocório e fixação, dentre outros.

A primeira chave dicotômica que possibilita a identificação de espécies de triatomíneos por meio da ornamentação dos ovos foi apresentada por AbALOs \& Wygodzinsky (1951), ao estudarem espécies de triatomíneos da Argentina. A partir de então, esse tipo de abordagem passou a ser bastante utilizada por diversos autores (BARATA, 1981, 1998; Rosa et al., 2000, 2003).

De acordo com os resultados obtidos neste estudo, os ovos de T. carcavalloi compartilham semelhanças tanto com os de $T$. rubrovaria quanto com os de $T$. circummaculata e os de T. infestans, com formato elipsóide, células exocoriais hexagonais, em sua maioria, perfurações esparsas de tamanho e forma indefinidos, ausência de "colo" ou "colarinho" e borda corial contígua ao plano do opérculo e da casca (BARATA, 1998; Rosa et al., 2000).

A descrição das ninfas é mais um critério usado na identificação das espécies de tritomíneos, mas ainda constitui um desafio uma vez que apenas $27 \%$ das espécies conhecidas tiveram suas formas imaturas descritas (JuRberg et al., 1991a; JuRberg \& Vogel, 1994; JURBERG et al., 2002).

As primeiras descrições dos estádios ninfais couberam a PINTO (1927), seguido por Usinger (1944) e LENT \& WYGODZINSKY (1979) que atualizaram a chave já existente para ninfas de $5^{\circ}$ estádio, incluindo ninfas de $1^{\circ}$ estádio a fim de proporcionar uma diagnose genérica.

As ninfas de T. carcavalloi se diferenciam de todas as espécies a ela relacionadas, principalmente pela coloração e tamanho.

Estes resultados constituem os primeiros relatos dos estádios imaturos dessa espécie, visando contribuir para a caracterização da mesma e ampliar o conhecimento sobre os triatomíneos. Abre ainda a possibilidade de rever o posicionamento desta espécie e, até mesmo, de $T$. rubrovaria no "complexo infestans" (CARCAVALLO et al., 2000) uma vez que ambas apresentam características morfológicas e distribuição geográfica muito semelhantes.

É imprescindível levar em consideração resultados recentes de estudos moleculares (HYPSA et al., 2002; SAINZ et al., 2004) que sugerem a criação de um novo "complexo infestans" com inclusão de T. circummaculata, espécie que pode ocupar o mesmo ecótopo de T. rubrovaria sendo, por vezes, encontradas juntas (Lent \& WyGodZINSKy, 1979; Rosa et al., 2000) e também os resultados aqui apresentados, corroborando a proximidade entre essas espécies.

Agradecimentos. Ao Serviço de Vigilância em Saúde/ Ministério da Saúde por auxiliar na captura dos exemplares; à técnica Vanda Cunha por coletar e manter os exemplares em nosso laboratório; ao Conselho Nacional de Desenvolvimento Científico e Tecnológico ( $\mathrm{CNPq})$.

\section{REFERÊNCIAS BIBLIOGRÁFICAS}

Abalos, J. W. \& Wygodzinsky, P. 1951. Las Triatominae Argentinas (Reduviidae, Triatominae). Universidad Nacional de Tucumán, Instituto de Médicina Regional Monografia 2, Public. 601:1-178.

Barata, J. M. S. 1981. Aspectos Morfológicos de ovos de Triatominae II - Características macroscópicas e exocoriais de dez espécies do gênero Rhodnius Stäl, 1859 (Hemiptera Reduviidae). Revista de Saúde Pública 15:490-542.

. 1998. Macroscopic and exochorial structures of Triatominae eggs/Estruturas macroscópicas e exocoriais de ovos de Triatominae. In: Carcavallo, R. U.; Galíndez Girón, I.; JuRberG, J. \& Lent, H. eds. Atlas dos vetores da doença de Chagas nas Américas. Rio de Janeiro, FIOCRUZ. v.2. p.409-448.

Carcavallo, R. U.; Otero, M. A.; Martinez, A. \& Tom, R. J. 1975. Notas sobre la biología, ecología y distribución geográfica del Psammolestes arthuri (Pinto), 1926 (Hemiptera, Reduviidae). Descripción de los estadios preimagales. Boletim de la Dirección de Malariologia e Sanidad Ambiental 15:231-239.

Carcavallo, R. U.; Justus, N. S. \& Martinez, A. M. 1978. Descripción de las ninfas de II, III y IV estadio de Alberprosenia goyovargasi Martinéz \& Carcavallo, 1977 (Hemiptera, Reduviidae, Triatominae). Observaciones com microscopia eletrónica de barrido. Boletim de la Dirección de Malariologia e Sanidad Ambiental 18:132-138.

Carcavallo, R. U.; Jurberg, J.; Lent, H.; Noireau, F. \& Galvão, C. 2000. Phylogeny of the Triatominae (Hemiptera, Reduviidae) proposals for taxonomic arrangements. Entomología y Vectores 7(1):1-99.

Costa, J. M.; Jurberg, J. \& Barth, M. O. 1991. Estudos morfológicos de Cavernicola lenti Barrett \& Árias, 1985 (Hemiptera, Reduviidae, Triatominae). Memórias do Intituto Oswaldo Cruz 86(2): 247-263

Galíndez-Girón, I.; Rocha, D. S.; Lent, H.; Carcavallo, R. U.; Jurberg, J.; Galvão, C.; Barbosa, H. S.; Martinez, A.; Barata, J. 
M. S. \& Rosa, J. A. 1999. Estadios Ninfais. In: Carcavallo, R. U.; Galíndez Girón, I.; Jurberg, J. \& Lent, H. eds. Atlas dos vetores da doença de Chagas nas Américas. Rio de Janeiro, FIOCRUZ. v.2. p.449-513.

Galliard, H. 1935. Recherches sur les Réduvidés Hématophages Rhodnius et Triatoma. V. Morphologie de l'ouef des Triatomes. Annales Parasitologie Humaine Compareé 13:511-527.

Galvão, C.; Carcavallo, R. U.; Rocha, D. S. \& Jurberg, J. 2003. A checklist of the current valid species of the subfamily Triatominae Jeannel, 1919 (Hemiptera, Reduviidae) and their geographical distribuition, with nomenclatural and taxonomic notes. Zootaxa 2002:1-36

Gonçalves, T. C. M.; Jurberg, J.; Costa, J. M. \& Souza, W. 1985. Estudo morfológico comparativo de ovos e ninfas de Triatoma maculata (Erichson,1848) e Triatoma pseudomaculata Correa \& Espínola, 1964 (Hemiptera, Reduviidae, Triatominae). Memórias do Instituto Oswaldo Cruz 80:76-280.

Hypsa, V.; Tiez, D. F.; Zrzavy, J.; Rego, R. O. M.; Galvão, C. \& Jurberg, J. 2002. Phylogeny and Biogeography of Triatominae (Hemiptera:Reduviidae): Molecular Evidence of a New World Origin of the Asiatic Clade. Molecular Phylogeny and Evolution 23:447-457.

JimÉnEZ, O. H. \& Fuentes, O. 1981. Triatoma flavida (Hemiptera: Reduviidae). I. Estudo biométrico de larvas. Revista Cubana de Medicina Tropical 33:195-200.

Jurberg, J.; Gonçalves, T. C. M.; Costa, J. M. C. \& SouZA, W. 1986. Contribuição ao estudo morfológico de ovos e ninfas de Triatoma brasiliensis Neiva, 1991 (Hemiptera, Reduviidae, Triatominae). Memórias do Instituto Oswaldo Cruz 81(1):111-120.

Jurberg, J.; Fagundes, L. M. \& Barth, O. M. 1991a. Estudo morfológico de ovos e ninfas de Diptalogaster maximus (Uher, 1894) (Hemiptera, Reduviidae, Triatominae). Revista Brasileira de Biologia 53:269-283.

Jurberg, J.; Galvão, C. \& Barth, O. M. 1991b. Estudo morfológico de ovos e ninfas de Triatoma nitida Usinger,1939 (Hemiptera, Reduviidae, Triaominae). Revista Brasileira de Biologia 51:365-372.

JuRberg, J. \& Vogel, M. 1994. Morfologia de huevos y ninfas de Triatoma matogrossensis Leite \& Barbosa, 1953 (Hemiptera: Reduviidae). Entomología y Vectores 1:167-177.

Jurberg, J. \& CAmpos, P. 1995. Morfologia de huevos y ninfas de Triatoma vitticeps (Stal,1859) (Hemiptera, Reduviidae). Entomología y Vectores 2:9-22.

Jurberg, J.; Lima, M. G.; Rocha, D. S.; Carcavallo, R. U. \& Galvão, C. 1998a. Descrição de ovos e ninfas de Triatoma melanosoma Martínez, Olmedo \& Carcavallo, 1987 (Hemiptera, Reduviidae). Entomología y Vectores 5(2):67-84.

Jurberg, J.; Rocha, D. S.; Lorosa, E. S.; Vinhaes, M. \& Lent, H. 1998b. Uma nova espécie de Triatoma do estado do Rio Grande do Sul, Brasil (Hemiptera, Reduviidae). Entomología y Vectores 5(6):295-310.

Jurberg, J.; Silva, M. B. A.; Galvão, C.; Rocha, D. S.; Barbosa, H.
S. \& Carcavallo, R. U. 2002. Descrição de ovos e estádios ninfais de Triatoma jurbergi Carcavallo, Galvão \& Lent, 1998 vistos através de microscopia ótica e eletrônica de varredura (Hemiptera, Reduviidae, Triatominae). Memórias do Instituto Oswaldo Cruz 97(2):209-216.

Lent, H. \& Wygodzinsky, P. 1979. Revision of the triatominae (Hemiptera, Reduviidae), and their significance as vectors of Chagas'disease. Bulletim of American Museum of Natural History 163:(3): 127-520.

Lorosa, E. S.; Jurberg, J.; Souza, A. L. A.; Vinhaes, M. C. \& Nunes, I. M. 2000. Hemolinfa de Dyctyoptera na manutenção do ciclo biológico silvestre de Triatoma rubrovaria (Blanchard, 1843) e Triatoma circummaculata (Stal,1859) Hemiptera, Reduviidae, Triatominae. Entomologia y Vectores 7(3):287-296.

Mascarenhas, B. M. 1987. Descrição dos estádios imaturos de Rhodnius brethesi Matta, 1919 (Hemiptera, Reduviidae). Boletim do Museu Paraense Emilio Goeldi Seção Zoologia 3:183-194.

Pinto, C. 1924. Biologia do Triatoma brasiliensis Neiva. Sciência Médica 2:541-543.

Pinto, C. 1927. Chave dos gêneros baseada na anatomia do rostro, tórax e inserções das antenas. Boletim de Biologia 8:103-114

Rocha, D. S.; Jurberg, J. \& Galvão, C. 1996. Descrição de ovos e ninfas de Triatoma lecticularia (Stäl, 1859) (Hemiptera, Reduviidae, Triatominae). Entomología y Vectores 3:123-135.

Rosa, J. A.; Barata, J. M. S.; Santos, J. L. F. \& Cilense, M. 2000. Morfologia de ovos de Triatoma circummaculata e Triatoma rubrovaria (Hemiptera, Reduviidae). Revista de Saúde Pública 34(5):538-542.

Rosa, J. A.; Justino, H. H. G. \& Barata, J. M. S. 2003. Diferença no tamanho de cascas de ovos de colônias de Panstrongylus megistus. Revista de Saúde Pública 37(4):528-530.

Ruas-Neto, A. L.; Corseuil, E. \& Cavalleri, A. 2001. Development of rupestrian Triatomines (Hemiptera, Reduviidae, Triatominae) following hemolymphagy on Blaberids (Blattodea: Blaberidae) in Rio Grande do Sul state, Brazil. Entomologia y Vectores 8(2):205-216.

Ruas-Neto, A. L. \& Corseuil, E. 2002. Hábitos, distribuição geográfica e potencialidades dos triatomíneos rupestres como vetores de doença de Chagas no Rio Grande do Sul, Brasil (Hemiptera, Reduviidae, Triatominae). Entomología y Vectores 9(2): 231-249.

Sainz, A. C.; Mauro, L. V.; Moriyana, E. M. \& García, B. A. 2004. Phylogeny of triatominae vectors of Trypanosoma cruzi suggested by mitochondrial DNA sequences. Genetics 121:229-240.

Silva, M. B. A.; Jurberg, J.; Galvão, C. \& Carcavallo, R. U. 2000. Estudo morfológico e morfométrico de ovos e ninfas de Triatoma guazu Lent \& Wygodzinsky, 1979 (Hemiptera, Reduviidae, Triatominae) vistos por microscopia óptica e eletrônica de varredura. Entomología y Vectores 7:311-334.

Usinger, R. L. 1944. The Triatominae of North and Central America and West Indies and their public health significance. Public Health Bulletim 288:1-83. 